\title{
Negotiation of Objects in Urban Kampong Street: A Case Study in Ampiun Alley, Cikini
}

\author{
Winda Hutami Tatyana ${ }^{1}$, Joko Adianto ${ }^{2}$, Rossa Turpuk Gabe ${ }^{2}$ \\ ${ }^{1}$ Undergraduate Student of Department of Architecture, Universitas Indonesia, Indonesia \\ ${ }^{2}$ Lecturer of Department of Architecture, Universitas Indonesia, Indonesia \\ Email address of corresponding author: rossa@ui.ac.id
}

\begin{abstract}
This paper aims to explore objects in the street of urban kampong to understand the social system and the spatial mechanism of the objects. Existence of objects and their formation are physical trails of social activities. The role of the object in social engagement can affect the street space and the behavior of its users. In urban kampong street, objects engaging in social activities, mainly in spatial negotiation. The case study was taken in Ampiun Alley of Kampong Cikini, one of the densest settlement in Central Jakarta. It was studied through observations, documentation, mapping, and interviews. In Ampiun Alley, various objects from transportation to domestic tools exist on the alley, while many passers-by are going through it. They were able to be tolerated because it did not give disadvantages to the street community, did not being an obstacle in circulation, and did not provide a slum-like image. We have discovered there are many different negotiation spaces produced following surrounding social condition and space needs. However, in general formation of objects was shaped through toleration and consensus activities, so it could avoid any possible conflict and maintain the primary function of the alley itself.
\end{abstract}

() 2018 IJBESR. All rights reserved.

Keywords: negotiation, object, social, street, urban kampong.

\section{Introduction}

Nowadays, the need of vacant land for dwelling place is increasing caused by the growing population. In Jakarta, the population has reached 9.99 million people, according to the 2015 BPS data [1]. As a consequence, dwelling infrastructure demands are incredibly high that they are developing and spreading. However, the limited land area did not change much. One modification to cope with this issue is by making an urban kampong in the middle of the city. Urban kampong is a high density, informal, and unplanned settlement area which dominated by low-incomes [2]. According to Silas, it generally has poor infrastructure, minimum social facilities, and overcrowding, compacted in a small area [3]. Thus, the need for additional space is urgent.
Kampong Cikini is one of the highly populated urban kampongs, with 3.784 residents settled in 1.5 hectares of the area according to 2014 data of Kelurahan Pegangsaan [1]. Its location between crucial sites made one of its main streets, Ampiun Alley, highly used by pedestrians, motorcyclists, and street vendors to pass through daily. Meanwhile, for the residents who live adjacent, the alley is seen as a solution for their spatial needs. It is proven by the existence of their personal belongings located on it, like a parked motorcycle. Placement of an object-regardless of its shape, dimension, and function - in such a narrow alley could affect its space and possibly blocks the way. 
Ampiun Alley was already narrow enough for movement, let alone stuffed with objects that changed its space. Hence, to meet the needs for additional space while fully maintaining its primary purpose, placing various objects is negotiated in the alley. It is an inevitable process to arrange a spatial mechanism to meet a desired physical condition. In short, this paper aims to; (1) Reveal the social system and the socio-spatial device that occurred, by using the objects as their physical trails. (2) Analyze how objects could affect the space of the street and how the other users respond.

\subsection{Negotiation as Social Activities}

Social activity is one of the essential human needs and desire. That is why humans are considered as the main actor in society. However, according to Actor-Network Theory (ANT), non-humans have an influence too in social activities, on an equal level with humans [4]. The non-humans are not only limited to inanimate objects, and it could be more than that, like nature, weather, politics, simply everything that revolve around human. Thus, the word 'actant' is used to cover both entities (humans and non-humans) as the word 'actor' is usually affiliated to humans exclusively [4]. Its role as the social actor is determined by how far it performed in the human dimension. For example, pen and paper; they are not the ones that initiate writing-a-letter activity, but, they do contribute to it so humans can communicate through a letter. Without them, said activity could not happen.

When these actants gather in a place and time, they shape and define each other, forming a network of relationship. The active network relation of heterogeneous actants produces social space [5]. It covers actants in their coexistence and interrelation [6]. Within the area, a politic of relation exists to confront differences of actants' diversity, a negotiation [7]. Negotiation activity arranges the space, leaving bodies of actants to manifest a physical condition.

\subsection{Conflict and Negotiating in Urban Kampong Street as Urban Public Space}

As a path, a street is where one can move within the existing channel [8]. But in the urban kampong, a street is not only the place where people are passing by, but also where inhabitants meet with neighbors, open their economy business, watch their children play, and many more. As a result, aside from its function as circulation space, socialization actively happens as well. Such trait is said to be a public space of the city, according to Jane Jacobs [9].

As a public space, a street in urban kampong hosts multiple functions and many kinds of people [9]. According to Kohn, urban spaces are integrated by overlapping public and private usages, due to some factors like ownership and accessibility [9]. Moreover, if space is limited like an alley, most inhabitants would do many things outside due to spatial issues. So, even though it is public property, it is mostly controlled by the private properties owners [9]. However, claiming space in public required a negotiation process, according to Goheen [9]. Kahn stated that street is a room of agreement, means that the linear space is formed through the accumulation of agreements—negotiations [10].

Such heterogeneous, overlapping usages, and users sometimes leads to conflict [9]. Conflict arises when a group of people has different ideas about public space; many of it happened between dwellers who live adjoining and other street users [9]. But, conflict should not always be seen as a negative thing, as it is a natural process within the shared public space [9]. However, Jurgen Habermas argues that discussion between parties are more civilized because it produces a general agreement (consensus) to meet desired purposes [9]. It 
does not have to be verbal but has to be practiced on-site [9]. From both conflict and consensus, changes can be made, thus affecting the space of urban kampong street from time to time.

On the other hand, there are several actions that people do not mind, and they do not wish for any changes. Thus, no consensus is required. Toleration is a very subjective and altruism matter. But as long as the actions are temporary and do not possess any threat to others, it should be publicly tolerated [9].

\section{Methods}

Ampiun Aley was chosen as a case study for five reasons; One, large varieties of street user, since it is located between crucial sites, such as Cikini Train Station, flower market (Pasar Kembang), traditional market (Pasar Cikini), jewelry center, Dr. Cipto Mangunkusumo Hospital, a grade school, as well a number of universities and offices. Two, it's only 1.5 to 1.8 meters in width. Three, both sides of the street meet the building's front facades. Four, an immense number of existing objects. Five, busier activities than surrounding alleys.

Data collection methodology is done through observations, documentation, mapping, and interviews. Observation is conducted on different days and time to see differences on the basis of the period. It is recorded through photos, videos, and mapping to know the placement, formation, and possible repetitive pattern. To obtain non-visual information, we interviewed some residents along Ampiun Alley intending to get a broader picture of social condition in the case study. The collected data is then analyzed using analytic description method of ANT, assisted with photos, mappings, and diagrams.

\section{Results and Discussions}

\subsection{Object in Ampiun Alley}

The most dominating group of objects in Ampiun Alley, which we group it into the first group, are motorcycles. Parking patterns are generally different every time, as it depends on any leftover space they could find. Although, owners would prefer a place with weather protection, if not in front of their houses. The second group is everything related to business belong to dwellers and hawkers as well. Most dwelling sellers protect their properties from the weather with stretched tarpaulins as a canopy, producing a shady place. However, it also attracts other actants; the most common are motorcycles. People often use the parked bikes for sitting, opening other activities possible, like chatting.

The third group plants; they provide visual aesthetic and some health aspect. Moreover, there are some big trees grow within some residents' front yard, creating a shady place similar to tarpaulin's. They are attracting other actants too. The fourth group is a culmination of objects, which are not as much as the other ones. There are trash cans, bird and chicken cages, sewer drain caps, canopies from tarpaulins, debris, wooden benches, plastic chairs, domestic tools, and laundries. Another non-human actor is a local rule that said object placement is limited within the gutter line (edge sides of the street). Generally, the dwellers obeyed the rule, but it could be influenced by the municipality police's occasional patrol. They are the government's staffs of security and order, responsible for keeping the people safe and disciplining everything out of the law according to standard.

According to ANT, there is a connection between objects that affect each other's presence and actions [4]. One example, covers of the gutter, while initially present for safety reasons, allow many objects to stand on it since they did not break the rule. As a result, they minimize space consumption, and their 
existence does not hinder passers-by unless they block the path. In short, sewer drain caps drive the affected people to tolerate the presence of objects. Any change of an actant's performance in the network can bring modifications to another network [4].

\section{Case 1: Arrangement Matter}

Due to no strict rules regarding opening a business in the community, Mrs. M (fried snacks seller), Mrs. N (chicken noodle seller), and Mr. O (stall owner) placed their stalls in front of their houses, close to each other. Mrs. $\mathrm{M}$ and N's stall consist of a table, a stove, cooking and eating equipment, and needed ingredients. Mrs. $\mathrm{N}$ also has her cleaning tools, and water vessel placed nearby so that she can rinse her dirty bowls. When the stalls are closed, they will bring their equipment inside and leave the tables outside. In Mrs. $\mathrm{N}$ case, she would flip her table upside down and set it aside so that a hawker can use her space. On the other hand, Mr. O's is simply a big box of a stall with a tarpaulin canopy.

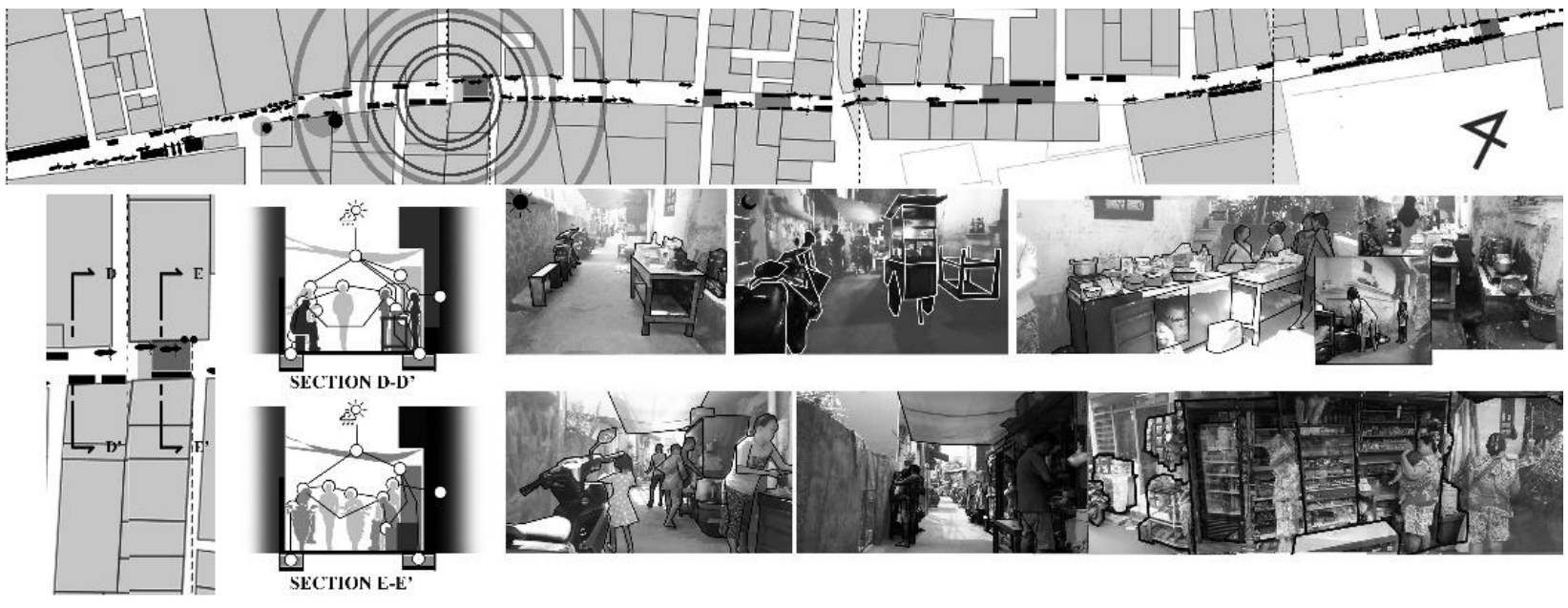

Figure 1: Physical Condition and Network of Case 1 and 2. Source: Tatyana, May 2018

The objects are standing on a sewer drain cap, but Mr. O's stall exceeded the specified line a little. However, the municipality police do not bother as the stuff are neatly arranged that they do not give the street a messy, slum-like image. However, he is warned to take down the tarpaulin (consensus), but the owner retains it (consensus fails). As a result, the stall, together with two other becomes a gathering spot. Mrs. $\mathrm{N}$ admitted that sometimes she could hardly sleep when they got very noisy. She tolerated it rather than complaining, resulting in people continuously come to that spot.

\section{Case 2: Positive Contribution to the is more positive than negative, so their Community}

The second case is about the first case's fried snacks and chicken noodle sellers. Their cooking activities are not only used up the narrow alley's space but also made the surrounding area warmer. They also create transaction and eating activities, which spent more spaces and may hinder the way. However, they are favored by neighbors and passing-by customers. According to Mrs. N, she chose to sell chicken noodle because of everyone like it. If she has sold cotton candy, kids will surely like it, but adults might not. Not only the food but also the shady place provided by the stall owner are warmly welcomed. Their contribution to the local area 
existence in the street is accepted (tolerated) and the existing formation is relatively fixed.

\section{Case 3: Different Kind, Different Affect}

The third case is about Mr. and Mrs. Z, distributors of mineral water (in bottles and gallons) and cooking gas (3 kg size cylinders). They built two storage racks, so their goods can be arranged vertically and used up less space than they needed. One of them placed across their house, atop a concrete sewer drain cap. In the same place, they used to have an open kitchen. However, the kitchen was disturbing the use of the alley, according to the head of RT 11. Thus, he offered them consensus to move their kitchen inside. The Zs fulfilled the offer temporarily (consensus), but then they moved the kitchen back outside again (consensus fails). The leader said that he had been told them many times afterward, but they keep breaking the consensus, so in the end, he just tolerated it. From Zs perspective, the land in front of their house belongs to them, so they can freely use it as they wish.

Unlike storage racks, the kitchen is seen as a nuisance even though it was located in the same place. Storage racks are tolerable as it does not give the same effect as the kitchen does. It proves that different actant brings different relations to the network. Compared to the stove, the rack is cleaner, compact, and is providing other's need for water and gas. But why their open kitchen is responded differently compared to the other ones within Ampiun Alley? It is likely because Mrs. Z's kitchen did not make foods for sale, so it gives nothing but smoke and heat to the local area.



Figure 2: Physical Condition and Network of Case 3. Source: Tatyana, May 2018

Case 4: The Impact of Social Status and Control

The fourth case is about Mrs. A, a fried snacks seller, and a bit of Mr. B, a nearby stall owner. Mrs. A has her fried snacks stall in front of her house since the 1990s. As one of the oldest seller, she is respected by newer neighbors, and they tolerated her stall's existence because she has been there from the beginning. However, from the economy point of view, she is suffering. Due to many new fried snacks sellers, her income has decreased significantly. Ironically, she could not complain since she believes that our prosperity is in God's hand. This is the reason behind her tolerance, even though she could offer some consensus and make a change for a better economic condition.

Mrs. A's stall is smaller than the others, consisted of a small table to place her fried snacks and tableware. There is also a 'kitchen box,' which with it she has to cook in a lowsitting position using a small chair with her back facing the street. Her body position mainly used up space, since her objects are within the safe zone. Meanwhile, the nearby Mr. B's stall exceeded the specified line, and he got warnings from the municipality police (consensus). However, he is ignoring them (consensus fails). Even though the officer's 
warning did not budge Mr. B, they did affect Mrs. A, who did not break any rule. According to her, whenever the officer is patrolling, she would roll up her tarpaulin and clean up any mess nearby her stall. The point is, she did not want to get trouble from the security officer, so she made changes to her stall space according to the security officer's expectation (consensus) whenever they patrol.

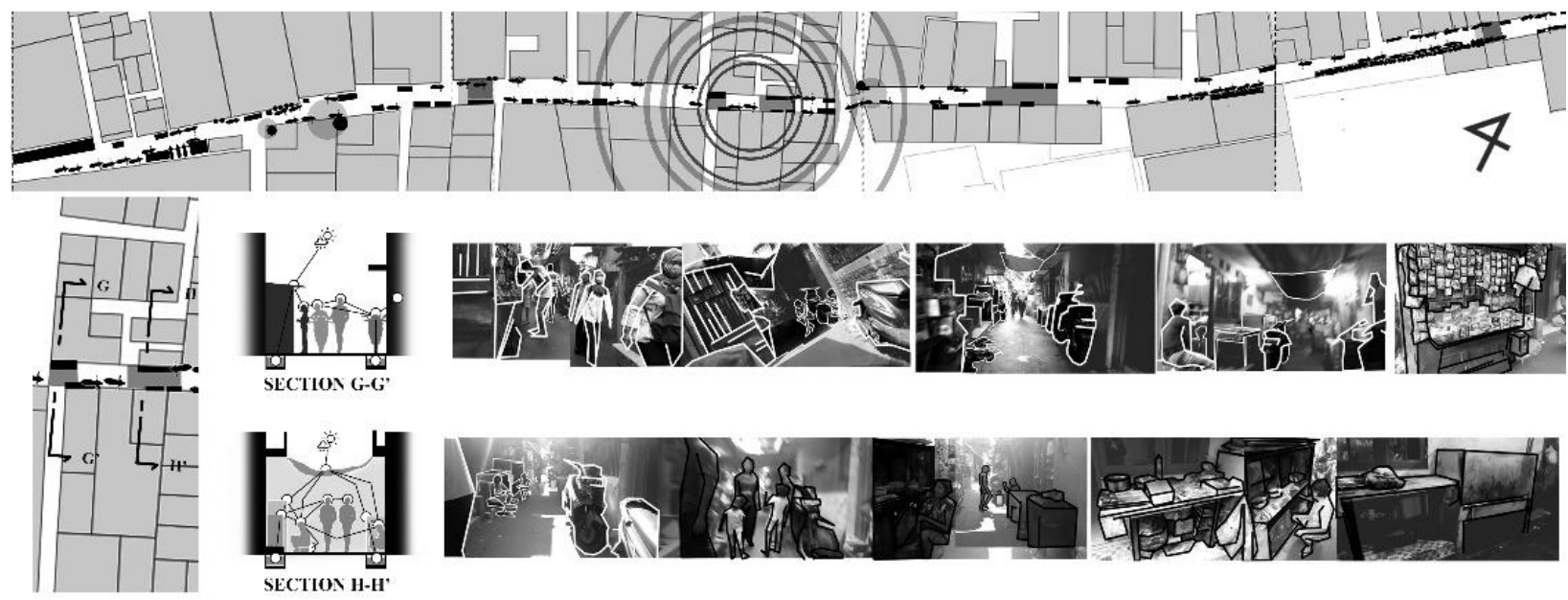

Figure 3: Physical Condition and Network of Case 4. Source: Tatyana, May 2018

\section{Case 5: Blending with Activities}

The fifth case revolves around three sellers nearby. The first is Mrs. R, who sell Soto Mie. Then, there is Mrs. T, who operates a stall in her house, and her sister Mrs. S, who sells home foods across the booth. Both food seller's stalls mainly consist of tables and food utensils. They also cook outside with a stove and cooking essentials. Mrs. S adds a chair for her to sit and a display rack. Mrs. T's stall goods are placed both inside and outside the building. The stuff on the outside is placed along with her domestic tools and trash. From top to bottom of the front facade, the objects are arranged messily, making a boundary between inside and outside of the stall.

Other than business-related stuff, they also do some domestic activities outside. Mrs. R and T are regularly cleaning tableware and washing laundry on the street side since there is a water source outside. Mrs. R was also drying her laundry nearby. To protect both objects and activities, three of them put tarpaulin canopies above them all. As a result, it invites people to hang out under it like other canopies, only here is denser. To make sure the others can circulate within their crowded space, the stuff was placed out of the way as much as possible. And when it is closing time, three of them will move their objects inside and leave stall furniture outside for extended parking space.

The short canopy, crowds of objects, and people with their business, domestic, and social activities, creating a personal atmosphere. Spaces formed of those activities are not only overlapped with each other but also blend into a new one. They bring out their personal spaces to the public space and domesticate it, making it like an extension of their living room. Moreover, the area is always crowded with people around the clock. In short, the existence of objects is tolerable due to the personal pressure applied in the formed space. 

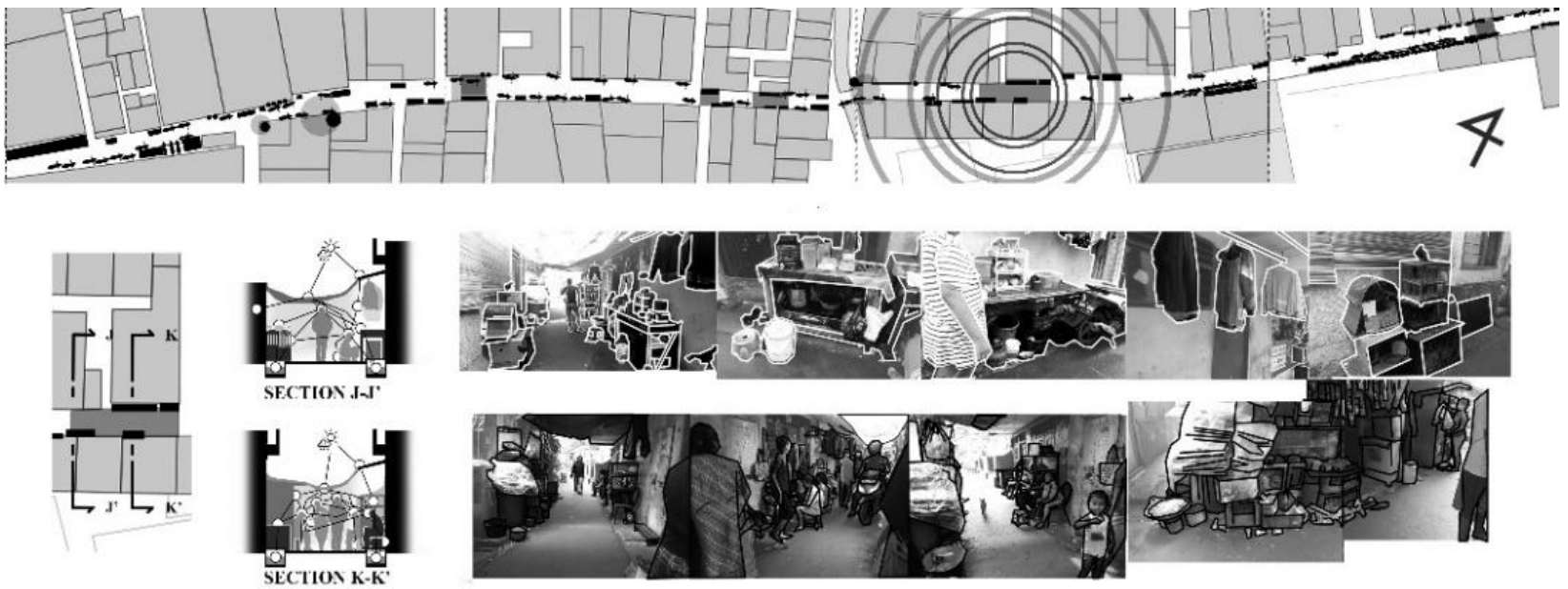

Figure 4: Physical Condition and Network of Case 5. Source: Tatyana, May 2018

\subsection{Negotiation Process of Objects in Ampiun Alley}

Kohn's theory of overlapping public and private spaces is confirmed to be present in Ampiun Alley [9]. For example, transactions are every day around stalls. Domestics activities are also spotted, like cleaning and doing the laundry. These include special activities as they are engaged with their individual objects. However, the most common activities are chatting and gathering, usually in any shady places. Private usages happen between people who use the public area to pass. The limited space in the house has forced them to bring their privacy out to the public space.

Ampiun Alley is a public space, but any open space has its limit [9]. The struggle to be accepted in public comes in different shapes, according to Ehrenfeught R, and LoukaitouSideris [9]. In five cases, they claimed an area in public and may become an obstacle to some extent. However, they have their way to negotiate in public to maintain their existence. The 1st case is compromised by trying not to give a visually unpleasant arrangement, even though they broke the rule. The 2 nd case is being beneficial to the local area. The 3 rd case is replacing objects to be tolerated. The 4th case is about the influence of social status and control. And the 5th case is applying personal pressure.

According to ANT, humans, and non-humans are connected through a network that affects each other [4]. Because each place's composed actants are different, they are forming a different network, negotiation mechanism, resulted in different physical manifestation. Case 3 explained different kind of objects could bring different impact, while case 1 and 4 's consensus is the object's formation to avoid conflict with the social controller. Meanwhile, case 2 and five negotiations are related to human's activities. In short, objects have a definite influence on human's social.

\section{Conclusion}

As a public space, urban kampong street has various usages and contain heterogeneous people. Therefore, it has a high rate of actants' relational network. It is visible through its physical trails, the existence of private properties within the public realm, such as personal belongings. In Ampiun Alley, the most dominant group objects are motorcycles, followed by objects related to the trading business, and plants. Lastly, there are other objects such as trash cans, fowl cages, sewer 
drain cap, canopies from tarpaulins, debris, wooden benches, plastic chairs, household tools, and laundries. These objects and humans are equal social actors, forming a relational network. Each space resulted are different, as it composed of different actants for each time and place. This is the reason behind the different social system and spatial mechanism of each area in Ampiun Alley. However, generally the reason is the rule of the tolerated area within the gutter line, to keep the function of the street well maintained, and social control actors (security officers) make sure it is well applied. Overall, objects are tolerated because they did not become an obstacle, giving advantages to other actants, and did not provide a slum-like image.

In conclusion, in a dense urban kampong street, each actant connects in the relational social network. Social activitiesnegotiation-forms social space that is accomplished in physical manifestation, through objects and their formation on the street. With a series of negotiations of tolerance and consensus, physical objects are arranged to avoid any possible conflicts while still maximize the function of urban kampong street.

\section{References}

[1] Ellisa E. Coping With Crowding in High-Density Kampung Housing of Jakarta. Internat. J Archit. 2016, 10(1): p 195-7.

[2] Colombijn F and Cote J. Cars, Conduits, and Kampongs: The Modernization of the Indonesian City. Leiden: Brill, 2014, p 123.

[3] Adianto J, Ellisa E, Okabe A, and Shima N. The Tenure Security and Its Implication to Self-Help Housing Improvements in the Urban Kampong: The Case of Kampong Cikini, Jakarta. URPL Rev. 2016 Mar; 3(4): p 50-65, available at https://www.jstage.jst.go.jp/article/urpr/3/0/3_50/_pdf/char/en.

[4] Latour B. Reassembling the Social: an Introduction to Actor-Network Theory. New York: Oxford University Press, 2005.

[5] Massey D. For Space. London: SAGE Publications Ltd, 2005.

[6] Lefebvre H. The Production of Space. NicholsonSmith D, translator. Oxford: Blackwell, 1991. p 71-73.
[7] Anderson B. For space (2005): Doreen Massey. Key Texts HG. Los Angeles: SAGE Publications. 2008. p 232.

[8] Lynch $\mathrm{K}$. Image of the city. Cambridge: Massachusetts Institute of Technology (M.I.T.) Press, 1960. p 41.

[9] Ehrenfeught R, and Loukaitou-Sideris, A. Sidewalks: Conflict and Negotiation over Public Space. Cambridge, MA: The MIT Press, 2009.

[10] Kahn LI. The Room, the Street and Human Agreement. 2012 Aug, available at https://www.japlusu.com/news/room-street-and-humanagreement. 